\title{
The strategic importance of Data Mining Analysis for Customer- Centric Marketing Strategies
}

\author{
Author Name \\ Valerio Veglio; Department of Business Studies, University of Milano-Bicocca, Italy
}

\begin{abstract}
The main challenge for companies is to identify accurate models and methods to predict winning competitive strategies. Data mining is becoming an astonishing approach for data analysis because the meaningful knowledge is often hidden in enormous databases and most traditional statistical methods could fail to uncover such knowledge. An efficient development of the customer relationship management and the data mining is the vital resource to collect and to manage this knowledge.

The purpose of this chapter is to demonstrate the strong relation between data mining and customer relationship management in order to forecast customer-centric marketing strategies. The last part of this chapter shows the results of an empirical research related to the identification of the main marketing and financial activities that could be leading customers in a credit-risk state. This research focuses the attention on the logistic regression model and on the criteria based on the loss function.
\end{abstract}

\section{INTRODUCTION}

The development of the internet and the World Wide Web have completely changed the way of marketing is done. They have made the process of collecting data easier, adding to volume of data available to business. Companies have realized that the knowledge in this enormous database is the key to supporting the various business decisions, in particular for the marketing function. Bueren, Schierholz, Kolbe and Brenner (2004) define knowledge as a strategic intangible resource at the base of the competitive advantages. Besides, the most important type of knowledge would appear to be customer knowledge. An efficient utilization of customer knowledge determines the development of firms. This is particularly true in marketing area because of the proliferation of customer data collect in the huge databases.

Customer data can be gathered through information systems and stored in a marketing dataset. Normally, these include contact data, interaction data, purchasing data, payment data and customer feedback (Wrycza, 2010). Most companies have Information Technology (IT) tools as Customer Relationship Management (CRM), Contact Service, Enterprise Resource Planning (ERP) and E-Business System for collecting customer data at every possible customer contact point (Rollins \& Halimen, 2005). These touch points include customer purchases, customer financial state payment, interaction or market research studies, sales force contacts, service and support calls, Web sites visits and satisfaction surveys (Kotler \& Armostrong, 2010). In this chapter, it is important to underline that CRM is considered not only as technology but also as managerial approach. In literature there is no universally accepted definition of CRM (Ling \& Yen, 2001; Ngai, 2005). Swift (2001) defines CRM as an "enterprise approach to understanding and influencing customer behavior through meaningful communication in order to improve customer acquisition, customer retention, customer loyalty, and customer profitability" (p.12). In fact, current competitive challenges induced by globalization and advance in information technology have forces companies to focus on managing CRM and in particular customer satisfaction, in order to optimize the future marketing investments and to increase the company's profitability. At this stage, it is clear that the relation between CRM and Data Mining is strong and 
fundamental to predict customer-centric marketing strategies. To do this, businesses must analyze the data collected in huge databases in a short time and in a significant way. Good judgment, intuition, and an awareness of the state of the economy may give a manager a rough idea or "feeling" of what is likely to happen in the future. According to Daniel Kahneman (Nobel in Economics, 2002) it is obvious as qualitative approaches are not enough for predicting accurate and significant marketing performance in today global business (Kahneman, 2011). In this scenario a new generation of statistical models is required to analyze vast amount of data collected in enormous databases. The main problem for companies is to understand which raw data could be contains competitive information thus relevant knowledge for getting strategic decision. But, often this potential competitive knowledge remains stored in dormant databases without to create new customer value for enterprises. For this reason Data Mining (DM) has become an astonish approach in order to discover hidden knowledge in huge databases. In the literature DM is considered as the process of discovering meaningful new correlations, patterns and trends by sifting through large amount of data stored in repositories, using pattern recognition technologies as well as statistical and mathematical techniques (Larose, 2010). There are two main reasons why organisations have not tapped the information. First, information is sometimes poorly managed. Second, many firms are either not aware that it is possible to use powerful statistical data processing tools or do not know how to use them. The need to do this has led to a rapid expansion in the use of business intelligence tools including data mining models. According to Belbaly, Benbya and Meissonier (2007) they are fundamental to convert raw data into information and to integrate this information throughout the enterprise to develop knowledge useful in decision-making process. "Customer information is obtained through filtering, integrating, extracting or formatting customer data. Transforming customer data into customer information, organizations use various information systems. The most importance of them is CRM, Business Intelligence and Customer Intelligence System" (Buchnowska, 2011). In fact, today the applications of data mining in CRM are an emerging trend in the market. "Analyzing and understanding customer behaviors characteristics is the foundation of a competitive CRM strategy, so as to acquire and retain potential customers and maximize customer value" (Ngai, Xiu \& Chau, 2009). Despite, its relevance, DM and its application to CRM has not been systematically studied. In fact, in literature there is a comprehensive lack about this. Also, research on CRM and the use of DM to support CRM is limited (Anderson, Jolly \& Fairhurst, 2007).

This chapter examines the relationship between customer relationship management and data mining analysis and shows that this relationship is fundamental and strong. It begins by reviewing the literature on CRM and DM. Then it discusses how the methods and applications of both have evolved and it explains the customer relationship management and data mining limits. Finally, it presents an empirical research that illustrates the relationship, benefits, approaches to implementation, and the limitations of data mining in customer relationship management. The empirical research focuses the attention on the financial state of the customer in order to discover the causes that could be a customer in a credit-risk situation.

\section{CONCEPTUAL BACKGROUND}

Customer relationship management (CRM) can be considered as a set of processes and enabling systems supporting a business strategy to build a long term, profitable relationship with specific customers (Ling \& Yen, 2001). As said before, although CRM has become widely recognized as an important business approach, there is no universally accepted definition on CRM (Ling \& Yen, 2001; Ngai, 2005). CRM can be considered as "the strategic use of information, processes, technology, and people to manage the customer's relationship with your company (marketing, sale, services and 
support) across the whole customer life cycle" (Kincaid, 2003, p. 41). Chang et al, (2002) discussed the importance of CRM in enhancing the ability of a firm to compete and retain key customers. Panagiotis et al, (2007) define CRM as optimizing values as profitability, revenue and customer satisfaction (what and why) by organizing around customer segments, fostering customer-satisfying behaviour and implementing customer-centric business models. Finally, Parvatiyar \& Sheth $(2001$, p.5) define CRM as "a comprehensive strategy and process of acquiring, retaining and partnering with selective customers to create superior value for the company and the customer. It involves the integration of marketing, sales, customer service, and the supply chain functions of the organization to achieve greater efficiencies and effectiveness in delivering customer value". In today global business, marketers must consider CRM as a managerial strategy according to which a company's goals can be best achieved through identification and satisfaction of the customers' stated and unstated needs and wants. "The goals of CRM are, on the one hand, to attract and retain more customers by providing more quickly good quality service; on the other hand, to reduce costs through the overall management of business process" (Feng, 2012, p.48). From this point of view, DM if suitably integrated with CRM could be very helpful in profiling prospects, understanding their needs, and in discovering and building relationships with them by providing the most suitable products and enhanced customer service. CRM integrates back and front office systems to create a database of customer contacts, purchases, financial customer state and technical support, among other services. This database helps the company to present a unified face to its customers, and improve the quality of the relationship, while enabling customers to manage some information on their own. Today, businesses have to focus their attention on the last part of the definition because to create right customer database is the first step for companies for developing a substantial data mining analysis and to break down the competitors on the market. Currently CRM can be defined as a business philosophy and strategy that puts the customer at the centre of business operations so as to increase profits by improving customer acquisition and retention. In the literature, the CRM framework can be classified into operational and analytical (Berson, Smith \& Thearling, 2000; He, Xu, Huang \& Deng, 2004; Teo, Davadoss \& Pan, 2006). In this chapter particular attention is posed on Analytical CRM. In this contest, Analytical CRM could be defined as an enterprise-wide approach used to optimize your customer's behaviour in order to raise marketing performance. In addition, databases are used to collect quantifiable data, and the ability to analyze and use these data is a driving force behind CRM adoption. For these reasons, companies have to invest lots of resources in Analytical CRM and in DM. Also, Analytical CRM joined with DM could help organizations to better discriminate and more effectively allocate resources to the most profitable group of customers. For this reason DM could be defined as "the process of extracting or detecting hidden patterns or information from large databases" (Berson et al., 2000; Lejeune, 2001; Ahmed, Berry \& Linoff, 2004). With comprehensive customer data, data mining technology can provide business intelligence to generate new business opportunities (Bortiz \& Kennedy, 1995; Fletcher \& Goss, 1993; Langley \& Simon, 1995; Lau, Wong, Hui \& Pun, 2003; Salchenberger, Cinar \& Lash, 1992; Su, Hsu \& Tsai, 2002; Tam \& Kiang, 1992; Zhang, Hu, Patuwo \& Indro, 1999). Appropriate DM tools, which are good at extracting and identifying useful information and knowledge from enormous customer databases, are one of the best supporting tools for making different customer relationship decisions (Berson et al., 2000). From this point of view it is obvious that organizations in order to predict relevance customercentric marketing strategies and to obtain a leading position in the market must develop a CRM philosophy joined with DM. In this competitive scenario, the most traditional statistical methods would not be appropriate in drawing customer-centric marketing strategies because they are based only on the past events. 


\section{MARKETING INTELLIGENCE AND HIGH CUSTOMER VALUE}

In the past for businesses to gain a leading position and to implement winning marketing strategies was sufficient to develop the traditional statistical methods. Nowadays, past and present insight and trend information are not enough to be competitive in the business. Organizations need to know more about the future and, in particular, about future trends, patterns, and customer behaviour in order to understand the market better. Traditional statistical methods have a real $360^{\circ}$ view of the enterprise or business, but they analyse only historical data about what has already happened. These methods helps gain insight for what was right and what went wrong in decisionmaking providing a rear view analysis. However, one cannot change the past, but one can prepare better for the future and decision makers want to see the predictable future, control it, and take actions today to attain tomorrow's goals. From this prospective data mining methods appear to be more prominent than statistical methods. DM allows changing raw data into business knowledge. Sato (2000) said that data mining analysis differs from the statistical data analysis.

According to the definition, it is possible to consider the main features that differentiate the statistical data analysis from data mining analysis. First, predictive data mining is governed by the need to uncover, in a timely manner, emerging trends, whereas statistical analysis is related to historical fact and based on observed data. Second, statistical analysis focused on finding and explaining the major sources of variation in the data. In contrast to this, data mining endeavours to discover, not the obvious source of variation, but rather the meaningful, although currently overlooked, information.

Therefore, statistical analysis and data mining are complementary. Statistical analysis emphasizes and removes the major part of data variation before DM is used. This explains why the data warehousing tool not only stores data but also contains and executes some statistical analysis programs.

\section{The Customer Relationship Management Process}

The effectiveness of marketing activities becomes a critical success factor in many business sectors. The marketing activities have to provide more concrete elements to increase the competitive advantage and achieve a "breakthrough" of sales. Organizations, in order to develop a CRM, thus Customer Centric Marketing Strategies, must face some new challenges as the discovery of new market sectors and the identification of customer segments with high profitability. This process can be defined by four elements of a simple framework: know, target, sell and service (Garvin, 1998). CRM requires the firm to know and understand its markets (market orientation) and customers (client orientation). This involves detailed customer intelligence in order to select the most profitable customers and identify those no longer worth targeting. Today, the definition proposed by Garvin could be extended because companies, in order to discover the most profitable clients and the no longer worth customers, they should develop a sophisticated data analysis. As a result of this, it is clear as the integration of DM with CRM is fundamental in order to draw and to predict relevant and significant customer centric marketing strategies. CRM also entails development of the offer: which products to sell to which customers and through which channel. In selling, firms use campaign management to increases the marketing department's effectiveness. Finally, CRM seeks to retain its customers through services such as call centers and help desks.

The realization of this process involves three phases:

1. Activities of collection and processing of customer data, which must be available to all agents for using within the company in order to achieve benefits. 
2. To transform data in information through synthesis activities with high added value.

3. To design consistent actions with the objective to provide services and to satisfy individual customer needs, with the aim of retaining existing customers and identifying prospects with higher potential.

This means that the first challenge for companies is to know and understand their customers. But, in the current scenario, how can we classify, manage and communicate in a personalized way with each of them?

The technology and the new role played by information to support decision making are the first answers. The technology is a crucial element insight the CRM process because it simplifies the storage, the access and manipulation of information, the development of Internet, wireless communications and web portals. The new collaboration technologies and data analysis allow many companies to differentiate from the competition and keep abreast in dynamic markets. The central issue is the integration of data from various enterprise sources (internal and external databases) and by strengthening of inside and outside enterprise channel communication.

Businesses must collect data in a single information system where different components interact and contribute in various ways to create value. The main aim is to transform the data into information that is useful not only to marketing, but to all business functions. In this context, and in particular in the treatment of customers "history", an important role is taken by the customer database, born from the need to facilitate communication processes focused and targeted to the knowledge of customers. In fact, the data collected in the customer database, if properly analyzed and organized, represent the highest source from which to draw new marketing strategies. The data are essential for a company and their volume is uncontrollably growing. However the true value is the knowledge that companies can derive from these. For this reason the DM provides a great support in the decision-making process. Once defined the customer profile through the analysis and the interpretation of the information collected in the database and using the different data mining methods, the company is able to deliver products and personalized offers in perfect harmony with the customer-centric logic. Furthermore CRM can be seen as a combination of several components. According to Swift (2001, p.12), Parvatiyar and Sheth (2001, p. 5) and Kracklauer, Mills, and Seifert (2004, p. 4), Customer Relationship Management consists of four dimensions:

1. Customer Identification. CRM begins with customer identification, which is referred to as customer acquisition in some articles. This phase involves targeting the population who are most likely to become customers or most profitable to the company. Elements for customer identification include target customer analysis, customer segmentation and bubble demand'. Target customer analysis lead seeking the profitable segments of customers through analysis of customers' underlying characteristics, whereas customer segmentation involves the subdivision of an entire customer base into homogenous clusters.

2. Customer Attraction. This is the phase following customer identification. After identifying the segment and bubble demand of potential customers, organizations can direct effort and resources into attracting the target customer segments.

3. Customer Retention. This is the central concern for CRM. Customer satisfaction is the essential condition for retaining customers. As such, elements of customer retention include logics of customer-centric marketing, loyalty programs and complaints management. The logics of customer-centric marketing refer to personalized marketing campaigns which are supported by analysing, detecting and predicting changes in customer behaviours. Thus, customer profiling, recommender system or replenishment systems are related to customer-centric 
marketing. Loyalty programs involve campaigns or supporting activities which aim at maintaining a long term relationship with customers. Specifically, churn analysis, credit scoring, service quality or satisfaction makes part of loyalty programs. As a consequence of this, in the last part of this chapter, it will be shows the main results of an empirical research related to the customers in a credit risk state.

4. Customer Development. This involves consistent expansion of transaction intensity, transaction value and individual customer profitability. The first and the main elements of customer development is the customer lifetime value indicator. Customer lifetime value analysis is defined as the prediction of the total net income a company can expect from a customer (Drew, Mani, Betz, \& Datta, 2001; Etzion, Fisher, \& Wasserkrug, 2005; Rosset, Neumann, Erick, \& Vatnik, 2003).

These four dimensions share the common goal of creating a deeper understanding of customers to maximize customer value to the organization in the long term and to predict customer-centric marketing strategies. In order to achieve this aim, DM become fundamental because it can help to accomplish such a goal by extracting or detecting hidden customer characteristics and behaviours from enormous databases.

\section{The Development of Data Mining Process}

Foley and Russuell (1998) said that the top three end uses of data mining are in the marketing area. The main data mining applications in management area are:

- Market-Basket. Identifies which products are jointly purchased with others for improving the layout of goods on the shelves and to increase sales of determinate products through promotions on items associated with them.

- Web-Click-Stream. To understand the dynamics of web navigation to improve the navigation on the sites and, in e-commerce sites, to accelerate the paths that promote the purchase.

- Profiling. Allows creating homogeneous profiles of customers, based on their past behaviour in order to involve them with customized products and services and offer them targeted promotions.

- Retention/Churn. Discovers homogeneous groups of customers, in terms of behaviour and personal characteristics, in order to retain existing customers and to minimize customers in a dropping out-risk.

- Scoring. A set of statistical methods used to associate a score to each customer; this score have to reflect the behave interest propensity. For instance, in the business field, in order to evaluate the potential of a prospect.

- Risk Management. A set of statistical methods used to calculate how much capital to allocate to hedge risk. The committee of central banks has established the need to measure: market, credit and operational risk.

- Mining Unstructured Data, such as Text. The text data is always unstructured. So data mining tools can help to mine the unstructured data to help the various organizations to get good out of the data.

To sum up DM can be defined as an iterative and dynamic process that typically involves the following phases:

- Identification of the business problem. Decision makers must be defining the business problem. In this phase, data miners and decision makers work closely in order to define the project objectives and the requirements from a business perspective. The project objective is then translated into a data mining problem definition. In this phase, data mining tools are not yet required.

- Selection, organization and pre-treatment of the data. At the first step, it is fundamental to identify the data sources. Usually companies take data from internal 
sources because are the most cheaper and reliable data channel. "The ideal data source is the company data warehouse, "a store room" of historical data that is no longer subject to changes and from which it is easy to extract topic databases of interest" (Figini \& Giudici, 2009). After the identification of the database and the creation of a data matrix is often necessary to carry out a process of preliminary cleaning of the data. This is a formal process used to find possible outliers so variable that exist but are not suitable for analysis. Finally, before starting the data exploration phase, it is necessary to check the contents of each variable in order to identify the possible presence of missing or incorrect data.

- Data exploration and transformation. Data miners collect, cleanse, and format the data because some of the mining functions accept data only in a certain format. Also, they identify quality problems of the data. Traditional statistical methods as position and dispersion index are used to explore the data. This phase is essential because it allows at the data miners and business analysts to select the most appropriate statistical methods for the next step of the analysis. This choice must consider the features and the quality of the data available. If the data collected are insufficient for the purpose of the analysis, data miners can be make a new data extraction.

- Identification of statistical methods. There are various statistical methods and many algorithms available for the data mining analysis. The choice of which method to use in the analysis is related to the problem being studied or on the type of data available. The data mining process is guided by more applications. For this reason, the classification of the statistical methods depends on the analysis's aim. In general, it is possible to group the methods into two groups: descriptive ${ }^{i i}$ and predictive ${ }^{\mathrm{iii}}$ (Giudici \& Figini, 2009).

- Modeling. Data miniers select and apply various mining functions because you can use different mining functions for the same type of data mining problem. Some of the mining functions require specific data types. Also, they must assess each model. In the modeling phase, a frequent exchange with the domain experts from the data preparation phase is required. The modeling phase and the evaluation phase are coupled. They can be repeated several times to change parameters until optimal values are achieved. When the final modeling phase is completed, a model of high quality has been built.

- Evaluation and comparison of the methods used and final choice. Data miners evaluate the model. If the model does not satisfy their expectations, they go back to the modeling phase and rebuild the model by changing its parameters until optimal values are achieved. In fact, to produce a final decision it is necessary to choose the best model from the various statistical methods available. The choice of model is based on the comparison of the results obtained. It is important to underline that in data mining it is not usually a good idea to use just one statistical method to analyze data. "Each method has the potential to highlight aspects that may be ignored by other methods" (Figini \& Giudici, 2009, p. 3).

- Interpretation of the model chosen and its use in the decision process. In this phase analysts decide how to use the data mining results and the marketers, after a significance interpretation of these, draw new strategic customer-centric marketing strategies. For this reason data mining is not only data analysis, but also the integration of the results in to the company process. Once the model has been chosen and tested with a data set, the classification rule can be generalized. Having seen the benefits it can get from data mining, it is crucial to implement the process correct in order to exploit it to its full potential. Obviously, the inclusion of the data mining process in the firms must be done gradually, setting out realistic aims and looking at the result along the way. It is important to underline that this 
process especially if joined with the CRM leads to cultural changes in the enterprises.

The final aim is for data mining is to be complete integrated with the other activities that are used to support organization decisions (Figini \& Giudici, 2009). During the process of integration it is possible to identify four stages:

1. Strategic phase. Data miners study the business procedures for identifying where data mining could be more helpful. At the end of this phase decision makers can determinate the business objective and set up the data mining pilot project. Also, they can establish the criteria for evaluating the project activated.

2. Training phase. This phase allows evaluating the data mining activities with more accuracy. According to Figini and Giudici (2009) a fundamental aspect of the implementation of a data mining procedure is the choice of the pilot project.

3. Creation phase. In this phase it is necessary to reorganize the business database and if possible to create a data warehouse. Then, it is important to develop the previous data mining prototype until the migration phase and to allocate personnel and time to follow the project.

4. Migration phase. At this stage all people must to be ready for change. The data mining process must be implemented with success.

\section{The impact of Data Mining in Customer Relationship Management}

Before the process can begin, companies must be in possession of customer data. The data preparation is vital for the success of CRM as the data for the tools comes from various sources. Organizations can learn about their customers through internal customer data or they can purchase data from outside sources.

An enterprise data warehouse is a critical component of successful customer-centric marketing strategies. The data warehouse can be defined as a container of all the data needed to carry out business intelligence operations (Giudici, 2009). Most firms have massive databases that contain marketing, human resources and financial information. Also, external sources of data or purchased database can be a key source for gaining customer knowledge advantage (Hill, 1999).

It should be clear that CRM is a broad topic with many layers, one of which is DM, and that DM is a method or tool that can aid companies in their strategies to become more customer oriented. DM is really important for the firms because it begins with a cleansing process that eliminates errors and ensures consistency. Additionally, the algorithms are then used to "mine" the data for modelling. Another DM advantages, in order to create high value for companies, is that it focuses the attention on consumers in respect of both the "internal" (price, product, positioning) and "external" (competition, demographic) factors that they to help determine the customer consumptions, customer satisfaction and corporate profits. Also, it provides a link between individual transactions and analytical system. This latter advantage represents the real connection with CRM. The relation between CRM and DM achieves to the company to manage a vast amount of data and to discover hidden relations with high business value. Finally, in order to create superior value, it is important to understand the meaning of the term "customer lifecycle" because it relates directly to customer revenue and customer profitability. Companies could increase the customer's value in three ways. First marketers can increase the customers use or purchases of products they already have. Secondly businesses could sell than more or higher-margin products and finally keep the customers for a longer period of time. Jones and Sasser (1995) give some general insights in the customer lifecycle: 
- Loyalists and Apostles: are the ground layers for the company. They deserve to receive constant attention. It is important to give customers ways to manifest their dissatisfaction. By properly responding, the company can conserve its loyal customers or reinforce their satisfaction.

- Hostages: in some circumstances, can leave and even transform themselves into terrorists. They can also decide not to leave and continue complaining. Companies have a tendency to spend vast amount of money to satisfy them without tangible results.

- Defectors: the company cannot accept their defection. By treating them well, company can keep them or even convert them into loyalist. It is once again important to let them express their dissatisfaction motives. However, the desire to satisfy each defector can be too onerous and counterproductive.

- Mercenaries: are and will remain out of control whatever the company may do. Companies do not have to care about them.

The customer lifecycle provide a good framework for applying DM to CRM. On the "input" side of data mining, the customer lifecycle tells what information is available. On the "output" side, the customer lifecycle tells what is likely to be interesting (Freeman, 1999). The outcome of this process is marketing data intelligence, which is defined as a combining data driven marketing and technology to increase the knowledge and understanding of customers, product and transactional data to improve strategic decision making and tactical marketing activity, delivering the CRM challenge (Chablo, 1999).

\section{CRM and Data Mining Disadvantages}

It is clear as the role of the technology is relevant in the CRM process but, it is not sufficient for building a profitable and lasting relationship. Past experiences showed that these misunderstanding was often penalizing for the organizations. For instance the main common CRM pitfalls are:

- Drawing the Customer-Centric Marketing Strategies after the implementation of CRM Process. Decision makers believe that implementing CRM software is equivalent to creating marketing strategies. As a first stage company must formulate this strategy and clarify the purpose for this.

- CRM implementation before the change of the Internal Organization. After establishing the goal of its strategy, the company have to revamp its organization and the business process accordingly. This includes not only external operations with customers but internal systems, such as job descriptions, performance measures, etc. If such reforms are implemented, employees will be able to recognize the nature and benefits of the new strategy.

- Assuming that more CRM technology is better. Many executives also mistakenly believe that CRM is a technology-intensive product and are apt to put emphasis on new function of CRM software. When a company begins to use package CRM software, it is very important for them to narrow down the specifications of the software in order to minimize the burden on its users and to suppress bugs. If a company concentrates excessively on new functions, this will cause false of integration of CRM software and existing system.

- Focus on customers. Organizations must establish contact only with individuals who have a real interest in their company and product. When they approach the wrong people, they can be perceived as stalkers and lose potential customers.

Instead, referring to DM pitfalls, it is possible to consider some limits as: 
- Privacy Issues. Because of the privacy issue some people do not shop on Internet. They are afraid that somebody may have access to their personal information and then use that information in an unethical way. Although it is against the law to sell or trade personal information between different organizations, selling personal information occurred. The selling of personal information might bring harm to these customers because you do not know what other companies are planning to do with the personal information that they have purchased.

- Security Issues. Although companies have a lot of information about us available online, they do not have sufficient security system in place to protect the information.

- Misuse of Information. Trends obtained through DM intended to be used for marketing purpose or for some other ethical purposes, may be misused. Unethical businesses or people may use the information obtained with the DM to gain over advantage vulnerable people or discriminate against a certain group of people.

- Cost of the Tools. The price of the data mining software is really high because of their complexity in terms of specific algorithms and models implemented in them. For this reason, firms sometimes cannot develop data mining analysis but just statistical analysis.

Moreover, in the recent years, the link between data mining software and campaign management was mostly non-automatic. It required that physical copies of the scoring from data model be created and transferred to the database. This separation of data mining and marketing management software introduce considerable inefficiency and was prone to human error. Today the trend is to integrate the two components in order to gain a competitive advantage. Businesses can gain a competitive advantages by ensuring that their data mining software and campaign management software share the same definition of the customer segments in order to modelling the entire database (Thearling, 1998).

\section{Data and Methodology}

The dataset analyzed was provided by a multinational company which sells book by correspondence. Customers, once become a partner of the company, must buy one purchase a month at least. If the customers do not purchase one time a month, they will receive the monthly book chosen directly from the company. For privacy reasons, it is impossible to provide other details about the company.

A cross-sectional design is used to accomplish the research goals. The original database available is composed by 65 variables and 12.624 customers. It contains information relating the clients who have received the monthly book in a given period. The main strength of this dataset is that, in order to ensure maximum accuracy of the results, the population was not sampled. The dataset is composed of quantitative and qualitative variables. The qualitative variables have been treated as a quantitative because they were categorized into classes. The target variable 'DWIMPPAG' is dichotomous, thus it can assume only two values: 0 if the customer does not pay (bad customer) or 1 if the customer pays (good customer). This variable provides the financial customer state.

Given the data available, predictive data mining models such as logistic regression model are an appropriate tool for predicting the average percentage of customer in a credit-risk state. In general, the regression models are a kind of statistical estimation technique used to map each data object to a real value provide prediction value (Carrier \& Povel, 2003; Mitra et al., 2002). Additionally, in order to evaluate the results of this model used the criteria based on the loss functions as Confusion Matrix and Roc Curve. 
The analysis starts with a brief investigation on the main variables in order to discover anomalies in the data as redundant variables and outliers. In this chapter the main attention is focused on the logistic regression model. This model is very appealing because it provides quick and robust results and it has been well studied and used in a lot of applications, especially, in management and marketing area. The detail of fitting the logistic regression model can be found in other research (Hosmer \& Lemeshoe, 1989 and Figini \& Giudici, 2009).

Lastly, in order to evaluate the performance of classification techniques, marketers usually use these criteria: percentage correctly classified (PCC) and area under the receiver operating characteristic curve (AUC). Both measures are commonly used as performance criteria (Mozer et. al., 2000; Zhang et al., 2002; Chawla et al., 2002). The PPC compares the 'posterior' probability of defection with the true status of the customer. The resulting confusion matrix is used to calculate the accuracy of the models. It contains the number of elements that have been correctly or incorrectly classified for each class. The main diagonal shows the number of observations that have been correctly classified for each class; the off-diagonal elements indicate the number of observations that have been incorrectly classified. A disadvantage of this measure is that it is not very robust concerning the chosen cut off value in the 'a posterior' probabilities (Baesens et al., 2002). The AUC measure takes into account all possible cut off levels. For all these points, it considers the sensitivity (the number of true positive versus the total number of events) and the specificity (the number of true negatives versus the total number of non-events) of the confusion matrix in a twodimensional graph, resulting in a ROC curve. The area under this curve can be used to evaluate the predictive accuracy of classification model (Hanley \& McNeil, 1982). For a comprehensive review, see Hand (1997).

\section{Results}

\section{Exploratory Analysis}

In this sub-section are provide some example of the main descriptive variables. It is clear that these variables, given their features, will not be introduced in the predictive model.

The graph below shows that the $24 \%$ of customers who could receive the monthly book have made, last year, one purchase in the store at least compared to $76 \%$ of customers that have not bough any books in the store.

Figure 1.Store purchase last year.

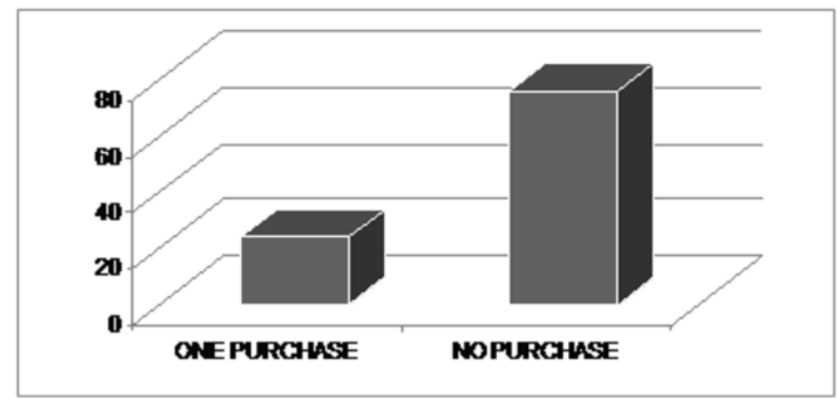

The next graph represents one of the main variables for this analysis and shows that $76 \%$ of customers did not receive the reminder payment ${ }^{\text {iv }}$. Just $23 \%$ of customers received the first remainder payment and only $1 \%$ of customer received the second 
reminder payment. The percentage of customers that receive the last reminder payment is completely irrelevant. This result would seem excellent because the number of customers in the credit-risk state seem minimal.

Figure 2.Remainder payment percentage.

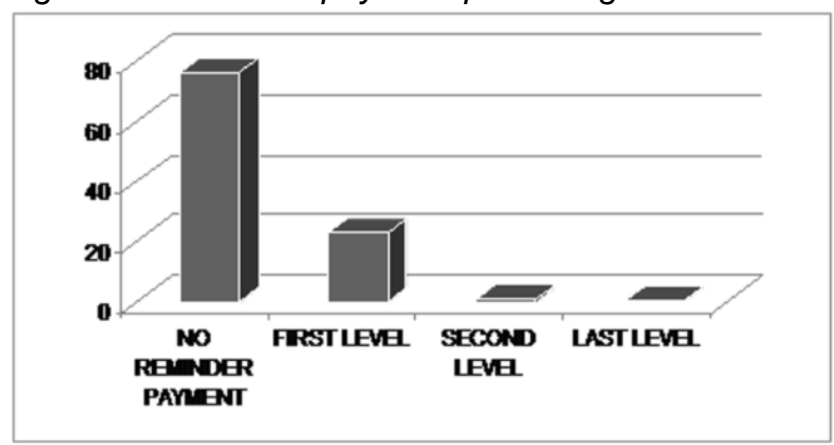

Finally, Figure 3 shows the recruitment channels of the company. It is clear that the main recruitment channel is agents and $c / \mathrm{cp}^{v}(88.87 \%)$. Additionally, from the graph it is possible to see that the company has not spontaneous customers.

Figure 3.Company recruitment channels.

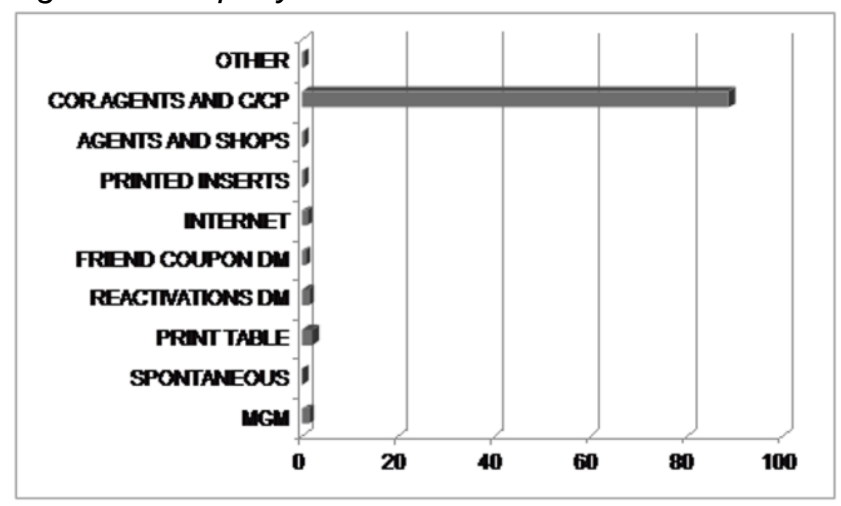

\section{Predictive Model}

Given the type of data, the logistic regression is one of the main models that marketers can implement. The target variable is dichotomous, thus it can assume only two values: 0 (bad client) and 1(good client). For the analysis was used, 'stepwise' methods, with a significance level of $p$-value vi. The 'stepwise' methods selects step by step the relevant explanatory variables for the analysis. It is important remember that in the logistic regression model does not possible to introduce qualitative variables. So, after the data manipulation and the exploratory analysis the number of variables decreased at 20 .

The table below shows the interaction between the target variable and the explanatory variables previously selected. Only the variables with $p$-value $<0.001$ are significant to predict the customer state. Variables with $p$-value $>0.05$ have to be eliminated from the model.

Table 1. Logistic Regression.

\begin{tabular}{|c|c|c|c|c|}
\hline & ESTIMATE & STD. ERROR & Z VALUE & p-value \\
\hline Number of orders sent & $-0,51520$ & 0,15352 & -3.356 & $0,000791\left(^{(* *)}\right.$ \\
\hline Number of orders return & $-0,44557$ & 0,07014 & -6.352 & $2,12 \mathrm{e}^{-10}{\left({ }^{* *}\right)}^{(*)}$ \\
\hline Number of orders paid & 0,51327 & 0,14774 & 3,474 & $0,000513\left(^{(* *)}\right.$ \\
\hline
\end{tabular}




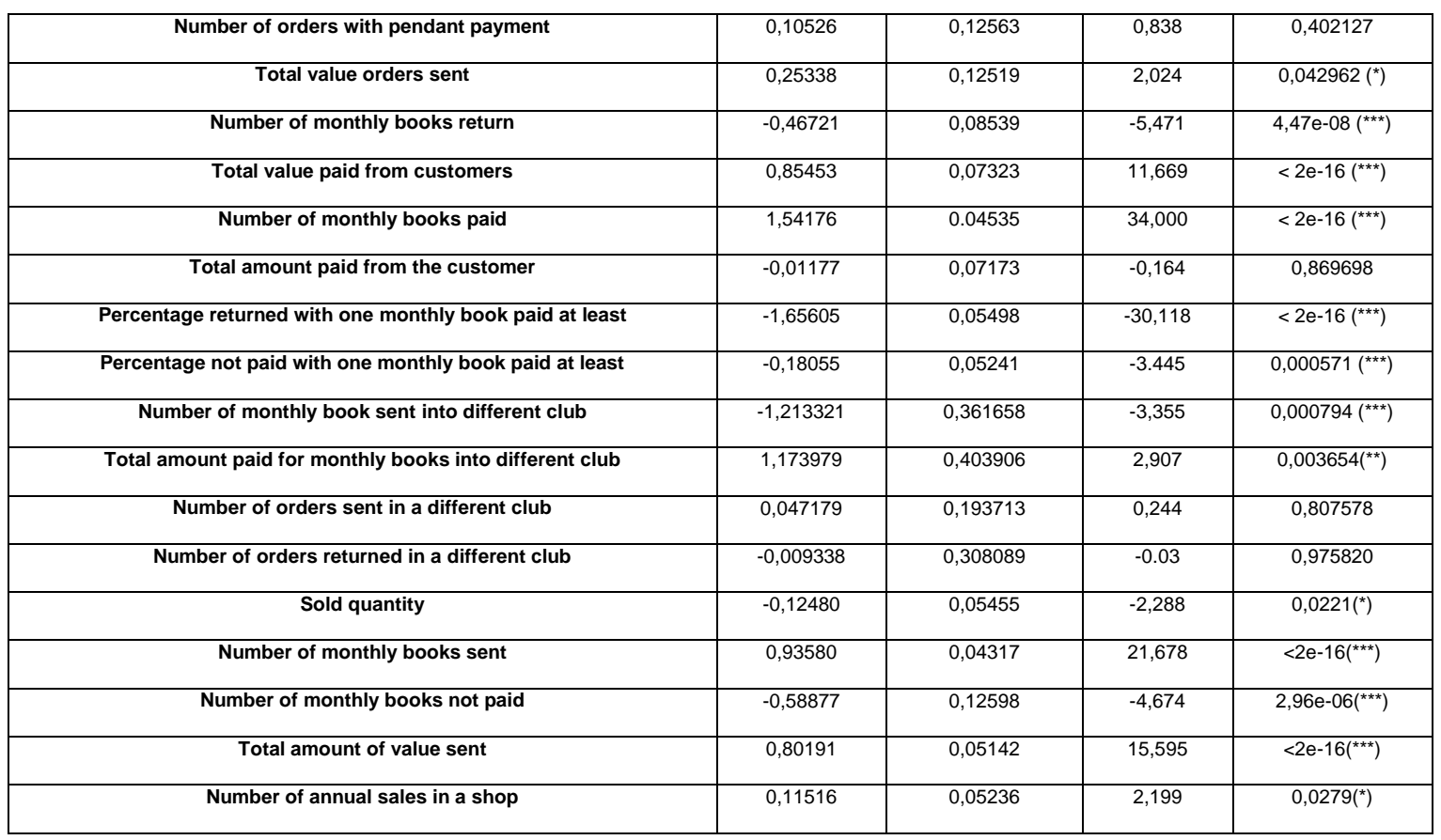

The overall goodness of the model is gives by the Akaike Index vii (AIC). In this case the value of AIC is 16.257 and the significant variables drop at 12 . Now, for a relevant accuracy of the analysis, it is necessary to revive the model considering only the variables with high significance, thus marketers must consider only the variables with $\mathrm{p}$-value less than 0.001 .

Table 2. Logistic Regression with high significant variables.

\begin{tabular}{|c|c|c|c|c|}
\hline & ESTIMATE & STD. ERROR & Z VALUE & $p$-value \\
\hline Number of orders sent & $-0,28441$ & 0,12875 & $-2,209$ & $0,0272\left(^{*}\right)$ \\
\hline Number of orders return & $-0,43856$ & 0,07006 & -6.260 & $\left.3,86 \mathrm{e}-10{ }^{(* *}\right)$ \\
\hline Number of orders paid & 0,61942 & 0,12639 & 4,901 & $9,54 \mathrm{e}-07\left({ }^{(* \star}\right)$ \\
\hline Total value paid from customers & 0,84507 & 0,04507 & 18,751 & $<2 \mathrm{e}-16\left(^{(* \star}\right)$ \\
\hline Number of monthly books paid & 1,54067 & 0.04485 & 34,352 & $<2 \mathrm{e}-16\left(^{(\star \star}\right)$ \\
\hline $\begin{array}{c}\text { Percentage returned with one monthly } \\
\text { book paid at least }\end{array}$ & $-1,65686$ & 0,05476 & $-30,254$ & $<2 \mathrm{e}-16{ }^{(* *)}$ \\
\hline $\begin{array}{l}\text { Percentage not paid with one monthly } \\
\text { book paid at least }\end{array}$ & $-0,18067$ & 0,05240 & -3.448 & $\left.0,0005655^{(* \star *}\right)$ \\
\hline Number of monthly books sent & 0,93616 & 0,04303 & 21,754 & $<2 \mathrm{e}-16\left({ }^{* * *}\right)$ \\
\hline Number of monthly books not paid & $-0,60061$ & 0,12569 & $-4,778$ & $1.77 \mathrm{e}-06\left({ }^{* \star}\right)$ \\
\hline Total amount of value sent & 0,76329 & 0,04200 & 18,175 & $<2 \mathrm{e}-16\left({ }^{* \star *}\right)$ \\
\hline
\end{tabular}

Following the reduction of variables the AIC value is decreased at 15.805 . This means that in the decision-making process this model is preferable than first. In the future, in order to minimize the number of the credit-risk customers must invest in all variables with high significance $\left.{ }^{* * *}\right)$. Also, Table 3 shows the result of the predictive model based on the logistic regression. Unfortunately this model underlines that the average of credit-risk customer (49.16\%) is moderately high.

Table 3. Predictive Model Result.

\begin{tabular}{|c|c|c|c|}
\hline MINIMUM VALUE & MEDIAN & AVERAGE & MAXIMUM VALUE \\
\hline $\mathbf{0 , 0 7 4 5 6}$ & 0,33600 & $\mathbf{0 , 4 9 1 6 0}$ & $\mathbf{0 , 8 4 6 1 0}$ \\
\hline
\end{tabular}

Comparing the logistic regression model with the results of the exploratory analysis is clear that the data mining approach leads unexpected results. In this case we can note 
that the probability of credit-risk customers is moderately high because the average value is equal to $49.16 \%$. As a result of the company must to change or to modify customer-centric marketing strategies and in particular must to develop a customer relationship process integrated to the data mining tools in order to discover every main causes that could lead customers in a credit-risk state.

\section{Model Evaluation}

In conclusion, in order to evaluate the correctness of the logistic regression model, marketers have to develop the criteria based on the Loss Functions (Confusion Matrix and Roc Curve). Table 4 notes that the model has classified correctly 20 observations about the category of good individuals out of 26 and 49 observations related to the category of bad individuals. In addition, it shows that the model's accuracy rate is $69 \%$ $(49+20) / 100$.

Table 4. Confusion Matrix.

\begin{tabular}{|c|c|c|c|}
\hline & ESTIMATED & ESTIMATED & \\
\hline ACTUAL & 0 & 1 & TOTAL \\
\hline 0 & $\mathbf{4 9}$ & 6 & 55 \\
\hline 1 & 25 & $\mathbf{2 0}$ & 45 \\
\hline TOTAL & 74 & 26 & $\mathbf{1 0 0}$ \\
\hline
\end{tabular}

This measure is not very robust concerning the chosen cut off value in the 'a posterior' probabilities. For this reason the figure below shows the predictive accuracy of the model previously carried out through the ROC Curve.

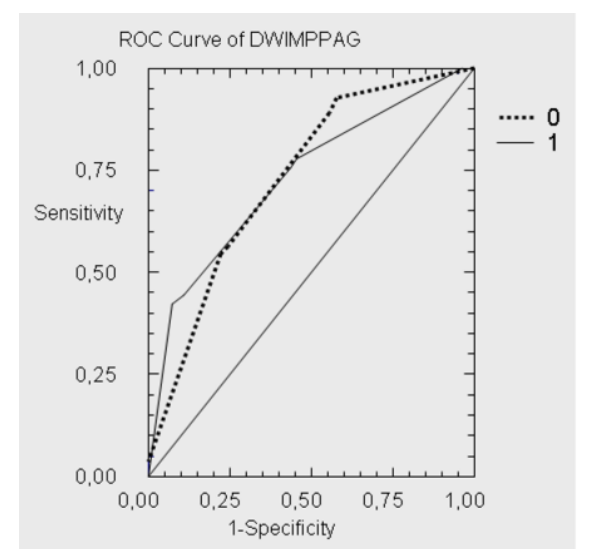

Figure 4. ROC Curve Target Variable 'DWIMPPAG'.

According to Sweet (1998) the model is moderate accurately because the AUC is equal to $73.03 \%$. In conclusion, it is clear that the criteria based on loss function have established that the result obtained by the predictive model is reliable.

\section{FUTURE RESEARCH DIRECTIONS}

This chapter focuses its attention on the data mining approach for the analysis of quantitative data. Today, it is important underline that in the management area, companies have the need to manage qualitative and unstructured data. For this reason, in order to minimize the forecast error rate and to draw relevant customercentric marketing strategies, it would be useful to develop new data mining tools that integrate in the same model structured and unstructured data ensuring a high level of 
predictive accuracy. For instance, data mining tools can help to mine unstructured data to help the various organizations to get good out of the data. Nowadays the challenge is to keep developing sophisticated techniques that assist companies in analyzing discovered knowledge easily and quickly. Additionally, given the dynamism of the data mining process, it would be interesting to extend these cross-cultural studies both on the same issue and on different issues. Marketers, with new data, could implement different data mining application such as market basket analysis, retention/churn analysis and web-click-stream analysis. Data mining could be really helpful in various situations and in all market industry.

\section{CONCLUSION}

The current economic crises have shown that corporation predictions are often inaccurate and inexact. In fact, business intelligence tools are one of the main priorities for the Chief Information Officer Director in every industry. But, despite this, due to the limited knowledge in this field, enterprises, in order to forecast significant customercentric marketing strategies, fall into huge traps obtaining catastrophic results. As said before, statistical methods are not enough to predict accurate customer-centric marketing strategies. This is demonstrated by the analysis discuss previously. In fact, with the data mining approach the average value of credit risk customers increase from $23 \%$ to $49.16 \%$. Unfortunately this value has been confirmed by the criteria based on the loss functions with a moderate accuracy. Despite this reality, many businesses usually consider some business intelligence tools such as data mining too complex, inaccurate and expensive, and very complicate for elaborating the final results. However, some predictive data mining models are simple to deduce and are really accurate. As a consequence of this, today, as never before, there is an emerging need to create a bridge between academic and marketing managerial reality. In this competitive scenario, the survival of companies is guaranteed by the search for a strategic competitive advantage in terms of knowledge. Firms must collect raw data into a database in order to uncover hidden relations through data mining methods and to draw winning customer-centric marketing strategies. The data entered in the database need to be integrated, reusable and non-volatile. Therefore, businesses should incorporate the best data mining tools to remove the short comings in their companies. An in-depth knowledge of their customers is essential to break down competitors. Prediction of behavior, customer value, customer satisfaction and customer loyalty are examples of some information that can be extracted from the data that should already be stored within a company database. However, to perform such a complex analysis of the information it is necessary to either purchase commercial software or implement a solution based on one of the many data mining techniques that have been developed for this purpose. As a result of this, it is clear as the key goal for enterprise is to discover hidden knowledge in huge databases and to make sense out of the data in order to improve the accuracy of customer-centric marketing strategies. According to Guido, Prete, Miraglia \& Marec (2011) "the accuracy of prediction could be help marketing practitioners deal with both prediction and targeting, as well as identify the variables that may affect response rate" (p. 1001). This mean that, companies must be able to analyze the customer data and understand in an effective and efficient manner their customers. Finally, the applications of DM in CRM are fundamental for understanding better the relationship between customers and companies in order to obtain higher profitability and a leading position on the market. In today global business, it is clear that DM is an astonishing approach for data analysis and it could become a new corporate key for predicting winning customer-centric marketing strategies. 


\section{REFERENCES}

Anderson, J., Jolly, L., \& Fairhurst, A. (2007). Customer relationship management in retailing: A content analysis of retail trade journals. Journal of Retailing and Customer Service, 14(6), 394-399.

Baesens, B., Viaene, S., Van den Poel, D., Vanthienen, J., \& Dedene, G. (2002). Bayesian neural network learning for repeat purchase modelling in direct marketing. European Journal of Operational Research, 47(3), 191-211.

Belbay, N., Benbya, H., \& Meissonier, R. (2007). An empirical investigation of the customer Knowledge creation impact on NPD Performance. In: Proceedings of the $40^{\text {th }}$ Hawaii International Conference on System Science.

Berry, M.J.A., \& Linoff, G.S. (2004). Data mining techniques for marketing, sales, and customer relationship management. New York, USA: Lohn Wiley \& Sons, Inc.

Berson, A., Smith, S., \& Thearling, K. (2000). Building data mining applications for CRM. New York, USA: McGraw-Hill.

Bortiz, J. E., \& Kennedy, D.B. (1995). Effectiveness of neural network types for prediction of business failure. Expert Systems with Applications, 9, 503-512.

Bueren, A., Schierholz, R., Kolbe, L., \& Brenner, W. (2004). Customer knowledge management-improving performance of customer relationship management with knowledge management. In: Proceedings of the $37^{\text {th }}$ Annual Hawail International Conference on System Sciences. IEEE.

Buchnowska, D. (2011). Customer Knowledge Management Models: Assessment and Proposal. Springer-Verlag Berlin Heidelberg, 93, 25-38.

Carrier, C.G., \& Povel, O. (2003). Characterising data mining software. Intelligence Data Analysis, 7, 181-192.

Chablo, E. (1999). The importance of marketing data intelligence in delivering successful CRM. www.crm-forum.com.

Chang, J., Yen, D., Young, D. and Ku, C. (2002). Critical issues in CRM adoption and implementation. International Journal of service technology and measurement, 3(3), 311-324.

Chawla, N.V., Bowyer, K.W., Hall, L.O., \& Kegelmeyer, W.P. (2002). Smote: Synthetic minority oversampling technique. Journal of Artificial Intelligence Research, 16, 321357.

Corniani, M. (2002). Demand Bubble Management. Symphonya - Emeriging Issue in Management (www.unimib.it/symphonya), 1.

Drew, J.H., Mani, D.R., Betz, A.L., \& Datta, P. (2001). Targeting customers with statistical and data-mining techniques. Journal of Service Research, 3, 205-220.

Etzion, O., Fisher, A., \& Wasserkrug, S. (2005). E-CLV: A modelling approach for customer lifetime evaluation in e-commerce domains, with an application and case study for online auction. Information Systems Frontiers, 7, 421-434.

Feng, F. (2012). Research of Customer Relationship Management Solutions Based on Data Mining. Information Engineering and Applications, 154, 47-52. 
Figini, S., \& Giudici, P.(2009). Applied Data Mining for business and industry. New York, USA: John Wiley \& Sons, Inc.

Foley, J., \& Russell, J.D. (1998). Mining your own Business. InformationWeek. The business value of technology. Retrieved on March, 22, 2012 from http://www.informationweek.com/673/73iudat.htm.

Fletcher, D., \& Goss, E. (1993). Forecasting with neural networks: An application using bankruptcy data. Information and Management, 3.

Freeman, M. (1999). The 2 customer lifecycles. Intelligence Enterprise, 2(16), 9.

Garvin, D.A. (1998). Building a Learning organization". Harvard Business Review on Knowledge Management. Harvard Business Press, Boston.

Giudici, P. (2009). Data Mining. Milano, Italy: McGraw-Hill.

Guido, G., Prete, M.I., Miraglia, S., \& De Marec, I. (2011). Targeting direct marketing campaigns by neural networks. Journal of Marketing Management, 27(9-10), 9921006.

Hand, D. (1997). Construction and Assessment of Classification Rules. New York, USA: John Wiley \& Sons, Ltd.

Hanley, J.A., \& McNeil, B.J. (1982). The meaning and use of the area under a receiver operating characteristic (ROC) curve. Radiology, 143(1), 29-36.

He, Z., Xu, X., Huang, J.Z., \& Deng, S. (2004). Mining class outliers: Concepts, algorithms and applications in CRM. Expert Systems with Applications, 27, 681-697.

Hill, L. (1999). CRM: easier said than done. Intelligence Enterprise, 2(18), 53.

Hosmer, D.W., \& Lemeshow, S. (1989). Applied logistic regression. New York, USA: John Wiley \& Sons, Ltd.

Jones, T.O., \& Sasser, W.E. (1995). Why Satisfied Customer Defect. Harvard Business Review, 11, 88-99.

Kahneman, D. (2011). Thinking, Fast and Slow. New York, USA: Ferrar, Straus Giroux.

Kincaid, J.W. (2003). Customer relationship management: Getting it right. New Jersey, USA: Prentice Hall PTR.

Kotler, P., \& Armstrong, G. (2010). Principles of marketing. New Jersey, USA: Pearson Prentice Hall.

Kracklauer, A.H., Mills, D.Q., \& Seifert, D. (2004). Customer management as the origin of collaborative customer relationship management. Collaborative Customer Relationship Management - taking CRM to the next level, 3-6.

Langley, P., \& Simon, H.A. (1995). Applications of machine learning and rule induction. Communication of the ACM, 38, 55-64.

Larose, D. (2010). Data Mining Methods and Models. New Jersey, USA: John Wiley \& Sons, Ltd. 
Lau, H.C.W., Wong, C.W.Y., Hui, I.K., \& Pun, K.F. (2003). Design and implementation of an integrated knowledge system. Knowledge-Based Systems, 16, 69-76.

Lejeune, M.A.P.M. (2001). Measuring the impact of data mining on churn management. Internet Research: Electronic Networking Applications and Policy, 11, 375-387.

Ling, R., \& Yen, D.C. (2001). Customer relationship management: An analysis framework and implementation strategies. Journal of Computer Information Systems, $41,82-97$.

Mitra, S., Pal, S.K., \& Mitra, P. (2002). Data Mining in soft computing frame work: A survey. IEE Transactions on Neural Networks, 13, 3-14.

Mozer, M.C., Wolniewicz, R., Grimes, D.B., Johnson, E., \& Kaushansky, H. (2000). Predicting Subscriber Dissatisfaction and Improving Retention in the Wireless Telecommunications Industry. IEE Transactions on Neural Networks, 11 (3).

Ngai, E.W.T. (2005). Customer relationship management research (1992-2002): An academic literature review and classification. Marketing Intelligence, Planning, 23, 582-605.

Ngai, E.W.T, Xiu, Li, \& Chau, D.C.K. (2009). Application of data mining techniques in customer relationship management: A literature review and classification. Expert System with Application, 36, 2592-2602.

Panagiotis, I., Soukakos, Nikolaos, B., Georgopoulos, \& Victoria, P.E. (2007). Two interrelated frameworks proposed for mapping and performance management of customer relationship management strategies. International Journal of Knowledge and Learning, 3(2-3), 299-315.

Parvatiyar, A., \& Sheth, J.N. (2001). Customer relationship management: Emerging practice, process, and discipline. Journal of Economic \& Social Research, 3, 1-34.

Rollins, M., \& Halinen, A. (2005). Customer Knowledge Management Competence:Towards a Theoretical Framework. In: Proceedings of the $38^{\text {th }}$ Hawaii International Conference on System Sciences.

Rosset, S., Neumann, E., Eick, U., \& Vatnik, N. (2003). Customer lifetime value models for decision support. Data Mining and Knowledge Discovery, 7, 321-339.

Salchenberger, L.M., Cinar, E.M., \& Lash, N.A. (1992). Neural networks: A new tool for predicting thrift failures. Decision Sciences, 23, 899-916.

Sato, Y. (2000). Perspective on data mining from statistical viewpoints. Knowledge Discovery and Data Mining. In: Current issues and New Applications, $4^{\text {th }}$ Pacific-Asia Conference, PAKDD, Kyoto, Japan.

Swift, R.S. (2001). Accelerating customer relationships: Using CRM and relationship technologies. New Jersey, USA: Prentice Hall PTR.

Tam, K.Y., \& Kiang, M.Y. (1992). Managerial applications of neural networks: The case of bank failure predictions. Management Science, 38, 926-947.

Teo, T.S.H., Devadoss, P., \& Pan, S.L. (2006). Towards a holistic perspective of customer relationship management implementation: A case study of the housing and development board, Singapore. Decision Support Systems, 42, 1613-1627. 
Thearling, K. (1998). Data Mining and Privacy: A conflict in the making? www.thearling.com.

Sweet, J.A. (1988). Measuring the accuracy of diagnostic system. Science, 240, 12851293.

Wrycza, S. (2010). Informatyka dla ekonomistow. Podrecznik akademicki. PWE.

Zhang, G., Hu, M.Y., Patuwo, B.E., \& Indro, D.C. (1999). Artificial neural networks in bankruptcy prediction: General framework and cross validation analysis. European Journal of Operational Research, 116, 16-32.

Zhang, Q., Varshney, P.K., \& Wesel, R.D. (2002). Optimal bi-level quantization of i.i sensor observations for binary hypothesis testing. IEE Transactions on Information Theory, 48 (7), 2105-2111.

\section{KEY TERMS AND DEFINITIONS}

Key words: network society, customer relationship management, data mining, customer centric marketing strategies, competitive advantage, customer knowledge, marketing database, exploratory analysis, statistical analysis, data mining analysis, logistic regression and Roc curve.

\section{Definitions:}

Competitive Advantages: company leading position in the market compared to competitors.

Customer Centric Marketing Strategies: set of marketing strategies primarily based on the customers desires.

Customer Relationship Management: corporate philosophy based on complete customers satisfactions with the main aim to develop long and durable customer relationships.

Customer Knowledge: set of the main relevant customer information and feature about their needs.

Data Mining Analysis: set of dynamic and interactive quantitative statistical methods suitable to analyze a large amount of data.

Data Mining: analysis of enormous database and detection of hidden relationships with high value for the companies.

Logistic Regression: dynamic predictive models based on the dichotomous target variables and a large amount of explanatory variables in order to understand the main relationships within variables.

Marketing Database: set of internal and external data regarding potential customers, clients and market features.

Statistical Data Analysis: set of a descriptive methods based only on historical data.

\section{ADDITIONAL READING SECTION}

Aeron, H., Kumar, A., \& Janakiraman, M. (2010). Application of data mining techniques for customer lifetime value parameters: A review. International Journal of Business Information System, 6(4), 514-529.

Au, S., Duan, R., \& Jiang, W. (2012). A data mining framework for product and service migration analysis. Analysis of operations research, 192(1), 105-121. 
Band, W.A. (1991). Creating Value for Customers. New York, USA: John Wiley \& Sons, Inc.

Baier, M., Ruf, K.M., \& Chakraborty, G. (2002). Contemporary database marketing: Concepts and applications. Evanston: Racom Communications.

Berry, M., \& Linoff, G. (2000). Mastering Data Mining. New York, USA: John Wiley \& Sons, Inc.

Brodie, R.J., Covellio, N.E., Brookes, R.E., \& Little, V. (1997). Towards a paradigm shift in marketing? An examination of current marketing practices. Journal of Marketing Management, 13, 383-406.

Broydrick, S.C. (1998). Seven laws of customer value. Executive Excellence, 15.

Butz, Howard, E., Jr., Leonard, D., \& Goostein (1996). Measuring Customer Value: Gaining the Strategic Advantage. Organizational Dynamics, 24, 63-77.

Carothers, Harlon, G., Jr, \& Mel Adams (1991). Competitive Advantage Through Customer Value: The Role of Value Based Strategies. Competing Globally Through Customer Value, 32-66.

Cassel, C.M. (2000). Measuring customer satisfaction on a national level using a super population approach. Total Quality Management, 11(7), 909-915.

Cheng, C-H., \& Chen, Y-S. (2008). Classifying the segmentation of customer value, via RFM model and RS theory. Expert System with Applications.

Christensen, R. (1997). Log-Linear Models and Logistic Regression. Berlin, Germany: Springer-Verlag.

Christopher, M., Payne, A. \& Ballantyne, D. (2002). Relationship Marketing: Creating Stakeholder Value. Oxford, UK: Butterworth-Heinemann Ltd.

Churchill, Gilbert, A., \& Carol Surprenant. (1982). An Investigation Into the Determinants of Customer Satisfaction. Journal of Marketing Research, 19, 491-504.

Day, George S. (1990). Market Driven Strategy: Processes for Creating Value. New York, USA: Free Press.

Datta, P., Masand, B., Mani, D.R., \& Li, B. (2001). Automated cellular modelling and prediction on a large scale. Issues on the Application of Data Mining, 485-502.

De Ville, B. (2001). Microsoft Data Mining, Integrated Business Intelligence for eCommerce and Knowledge Management. New York: USA: Digital Press.

Ellis, P.D. (2004). Market orientation and marketing practice in a developing economy. European Journal of Marketing, 39, 629-645.

Figini, S., \& Giudici, P. (2008). Statistical models for e-learning data. Statistical Methods and Applications.

Fildes, R., Nikolopoulos, K.,Crone, S.F., \& Syntetos, A.A. (2008). Forecasting and operational research: A review. Journal of the Operational Research Society, 59(9), 1150-1172.

Gale, Bradley T. (1994). Managing Customer Value. New York, USA: Free Press. 
Greenacre, M. (1983). Theory and Applications of Correspondence Analysis. New York, USA: Academic Press.

Griffin, A., \& John R.H. (1993). The Voice of the Customer. Marketing Science, 12, 127.

Gronroos, C. (2000). Service Management and Marketing: A customer Relationship Management Approach. Chichester, UK: John Wiley \& Sons Ltd.

Hamel, G., \& Prahalad, C.G. (1994). Competing for the Future. Boston, USA: Harvard Business School Press.

Hand, D.J., Mannila, H., \& Smyth, P. (2001). Principles of Data Mining. Cambridge, UK: MIT Press.

Li D.G., Dai, W.L, \& T-seng, W.T. (2011). A two-stage clustering method to analyze customer characteristics to build discriminative customer management: A case of textile manufacturing business. Expert System with Applications, 38(6), 7186-7191.

Mardia, K.V., Kent, J.T., \& Bibby, J.M. (1979). Multivariate Analysis. London, UK: Accademic Press.

Moller, K. \& Halimen, A. (2000). Relationship Marketing Theory: its Roots and Direction. Journal Marketing Management, 16, 29-59.

Morgan, R., \& Hunt, S. (1994). The Commitment-Trust Theory of Relationship Marketing. Journal of Marketing, 58(7), 20-38.

Namvar, M., Khakabimamaghani, S., \& Gholamian, M.R. (2011). An approach to optimised customer segmentation and profiling using RFM, LTV, and demographic features. International Journal of Electronic Customer Relationship Management, 5(34), 220-235.

Ngai, E.W.T., Xiu, L., \& Chau, D.C.K. (2009). Application of data mining techniques for customer lifetime value parameters: A review. Expert System with Applications, 36(2), 2592-2602.

Ram, S., \& Khatri, V.A. (2003). A comprehensive framework for modelling set based business rules during conceptual database design. Information System, 89-118.

Rygielski, C., Wang, J., \& Yen, D.C. (2002). Data mining techniques for customer relationship management. Technology in Society, 24, 483-502.

Rust, R.T., \& Zahorik, A.J. (1993). Customer satisfaction, customer retention, and market share. Journal of Retailing, 69, 193-215.

Tao, Y.H., \& Yeh, C.R. (2003). Simple database marketing tools in customer analysis and retention. International Journal of Information Management, 23, 291-301.

Verhoef, P.C., Spring, P.N., Hoekstra, J.C., \& Leeflang, P.S.H. (2002). The commercial use of segmentation and predictive modelling techniques for database marketing in the Netherlands. Decision Support System, 34, 471-481. 
i Temporary group of purchasers, held together by a shared interest in the specific features of an offering from a certain company (Corniani, 2002).

ii The main objective of this class of methods is to describe groups of data in a succinct way, for instance is possible to consider cluster analysis, Kohonen maps, association methods, loglinear models and graphical models. In descriptive methods there are no hypotheses of causality among the available variables.

iii In this class of methods the aim is to describe one or more of the variables in relation to all the other. The main methods of this type are those developed in the field of machine learning such as neural networks and decision trees, but also classic statistical model such as linear and logistic regression.

iv Customers can receive in total three payment remainder. If customers receive the last remainder will be automatically excluded.

${ }^{\vee} \mathrm{C} / \mathrm{cp}$ means postal voucher.

vi $\mathrm{P}$-value is the estimate probability of rejecting the null hypothesis of a study question when that hypothesis is true. When presenting $p$-value some groups find it helpful to use asterisk rating system as well as quoting the $\mathrm{p}$-value: $\mathrm{P}<0.05\left(^{*}\right) ; \mathrm{P}<0.01\left(^{* *}\right)$ and $\mathrm{P}<0.001\left(^{* * *}\right)$.

vii The index takes into account both the statistical goodness of fit and the number of parameters that have to be estimated to achieve this particular degree of fit, by imposing a penalty for increasing the number of parameters. Lower values of the index indicate the preferred model, that is, the one with the fewest parameters that still provides an adequate fit to the data." 